\title{
Review
}

\section{Sources of unintentionally produced polychlorinated naphthalenes}

\section{Guorui Liu ${ }^{\mathrm{a}, \mathrm{b}}$, Zongwei Cai ${ }^{\mathrm{b}}$, Minghui Zheng ${ }^{\mathrm{a}, *}$}

a State Key Laboratory of Environmental Chemistry and Ecotoxicology, Research Center for Eco-Environmental Sciences, Chinese Academy of Sciences, P.O. Box 2871, Beijing 100085, China

${ }^{\mathrm{b}}$ Department of Chemistry, Hong Kong Baptist University, Kowloon Tong, Kowloon, Hong Kong Special Administrative Region

\section{H I G H L I G H T S}

- PCN formation mechanisms during thermal processes are discussed.

- PCN emission levels from a number of industrial thermal processes are compared.

- PCN congener profiles from different sources are presented and compared. - PCN emission factors from a number of industrial thermal processes are summarized.

\section{G R A P H I C A L A B S T R A C T}

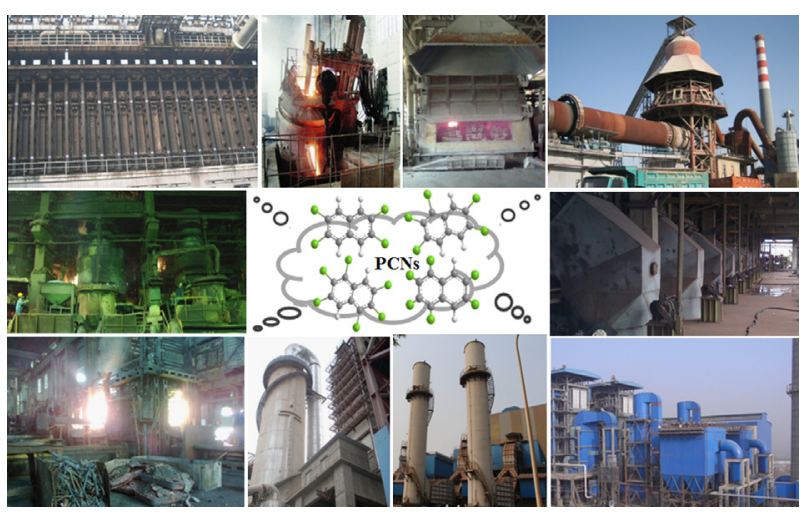

\begin{abstract}
A B S T R A C T
The European Union has proposed that polychlorinated naphthalenes (PCNs) should be included in the annexes of the Stockholm Convention on Persistent Organic Pollutants, signifying that there will be an increase in activities aimed at reducing PCN emissions. It has been speculated that the unintentional formation and emission of PCNs from industrial activities are the main current sources, because they have ceased to be manufactured as industrial chemicals in many countries. In this review, we provide a brief overview of recent progress in research into the unintentional formation and emission of PCNs from various industries that use thermal processes. The sampling and analysis of PCNs, and their formation mechanisms during thermal processes, are reviewed and discussed. The emission levels, emission profiles, and emission factors of PCNs from a number of industries that use thermal processes are summarized and compared, and this will provide helpful information for planning PCN source control measures and studying the source-receptor relationships of PCNs.
\end{abstract}

(c) 2013 Elsevier Ltd. All rights reserved.

\section{Contents}

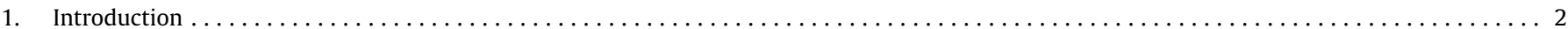

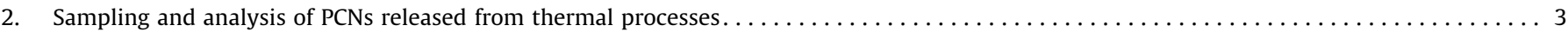

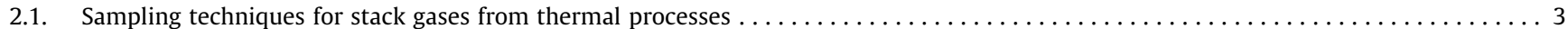

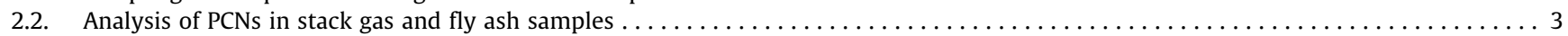

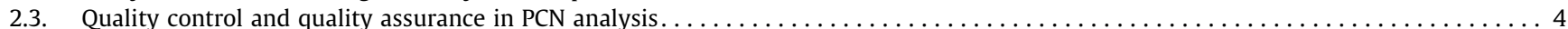

\footnotetext{
* Corresponding author. Tel.: +86 106284 9172; fax: +86 1062923563.

E-mail address: zhengmh@rcees.ac.cn (M. Zheng).
} 


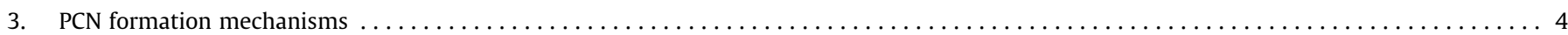

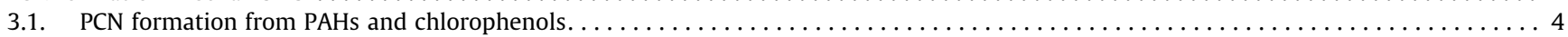

3.2. Formation of more chlorinated $\mathrm{PCN}$ homologs by the chlorination of less chlorinated homologs $\ldots \ldots \ldots$

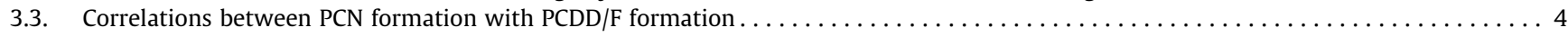

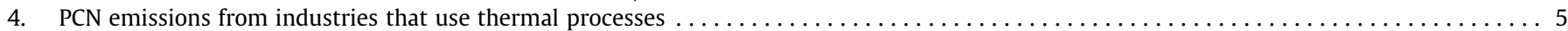

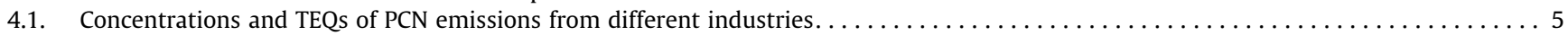

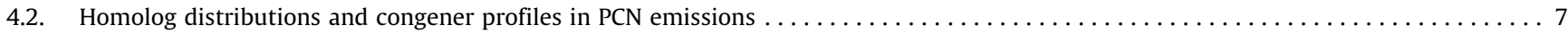

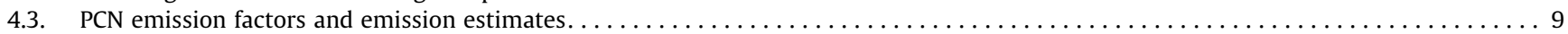

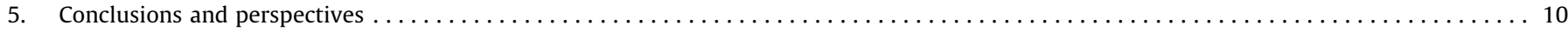

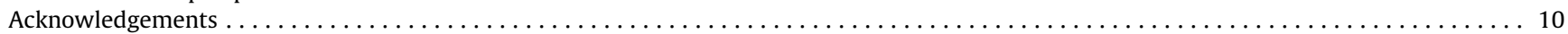

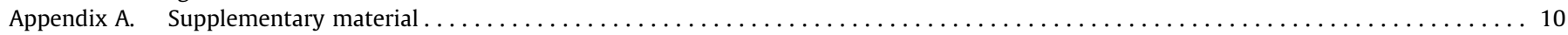

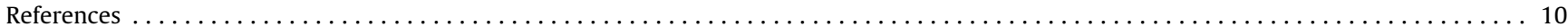

\section{Introduction}

Polychlorinated naphthalenes (PCNs) are a group of compounds that consist of a naphthalene molecule with one to eight chlorine substituents, with 75 possible congeners (Olivero-Verbel et al., 2004; Bidleman et al., 2010). The PCN structure is shown in Fig. 1. The commonly used numbering system for the 75 congeners, and their chlorine substitution positions on the naphthalene skeleton, are presented in Table 1. PCNs are toxic, persistent, lipophilic substances (Falandysz et al., 1997; Kilanowicz and SkrzypinskaGawrysiak, 2010; Kilanowicz et al., 2011, 2012). PCNs were selected as candidate persistent organic pollutants (POPs) in 2002 by the United Nations Economic Commission for Europe POP Protocol (Lerche et al., 2002), and PCNs have recently been proposed for inclusion in Annexes A, B, and/or C of the Stockholm Convention on POPs, signifying that activities for controlling PCN source emissions and reducing their environmental exposure may be obligatory in the near future.

PCNs show similar toxic mechanisms to polychlorinated dibenzo-p-dioxins and dibenzofurans (PCDD/Fs), inducing aryl hydrocarbon receptor (AhR) mediated responses, and are often referred to as dioxin-like compounds (Blankenship et al., 2000; Villeneuve et al., 2000). Although many studies have been carried out to evaluate the relative potency factors (RPFs) for individual PCN congeners relative to 2,3,7,8-tetrachlorodibenzo-p-dioxin (2378-TCDD) (Hanberg et al., 1990; Blankenship et al., 2000; Kannan et al., 2000; Villeneuve et al., 2000; Behnisch et al., 2003), there are currently no internationally authorized toxic equivalency factor (TEF) schemes for the PCN congeners. Some RPFs for individual PCN congeners have been proposed and used to evaluate the toxicities of PCNs in some studies, and the RPFs that have been published are summarized by Noma et al. (2004), Guo et al. (2008). A recent study (Hootha et al., 2012) gave estimated RPF ranges, from dose to response assessments, of $0.0015-0.0072$ for CN66 and 0.00029-0.00067 for CN67. Computational models have been developed to allow the relative potencies (REPs) of the PCN congeners to be predicted (Puzyn et al., 2007), and these estimated REPs ranged from $4.3 \times 10^{-9}$ to $3.2 \times 10^{-2}$, the highest values being for CNs 66, 67, 70, and 73. The values derived from the computational models (Puzyn et al., 2007) were higher than that from dose to re-

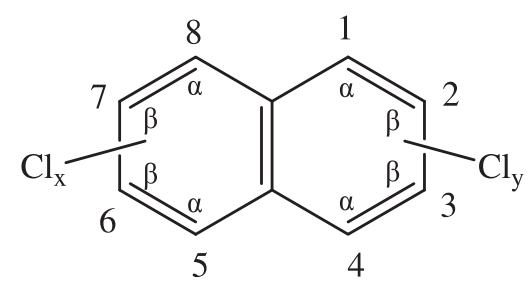

Fig. 1. Polychlorinated naphthalene structure, with the $\alpha$ and $\beta$ positions and the carbon atom numbers marked. sponse assessments for some congeners (Noma et al., 2004), such as CN66, 67, 70 and 73.

The occurrence of PCNs in the environment, and human exposure to them, have caused an increasing amount of public attention, and PCNs in aquatic animals and human dietary exposure have been reviewed several times (Falandysz, 2003; Domingo, 2004; Fernandes et al., 2010). PCN concentrations have also been measured in various environmental matrices in a number of regions (Jarnberg et al., 1997, 1999; Helm et al., 2003; Krauss and Wilcke, 2003; Helm et al., 2004; Jaward et al., 2004; Herbert et al., 2005; Lee et al., 2007; Ishaq et al., 2009). Studies of PCNs in the environment have shown that PCNs can contribute a greater proportion than the PCDD/Fs and polychlorinated biphenyls (PCBs) to the dioxin-like toxicity (i.e., the toxic equivalence, TEQ) in soils, sediments, and biota in specific areas that are surrounded by industrial plants (Kannan et al., 1998, 2001). The PCN TEQ in biota from polar environments accounts for about $10 \%$ or more of the sum of the PCDD/F, dioxin-like PCB, and PCN TEQs (Bidleman et al., 2010). Human exposure to PCNs and concentrations in human fat have been investigated in a number of regions (MartiCid et al., 2008; Fernandes et al., 2010; Horii et al., 2010; Schiavone et al., 2010), and, in a recent study, Park et al. found that the PCN TEQs in some human serum samples, calculated using the TEFs reported by Puzyn et al. (2007), were comparable with the PCDD/F and PCB TEQs (Park et al., 2010). Furthermore, the authors suggested that industries that involve thermal processes might be PCN sources to humans, because of the PCN profiles found in the serum samples (Park et al., 2010). Studies of PCNs are now attracting increasing attention because of their potential for causing environmental and human health risks.

The major sources of PCNs to the environment have been the historic production and release of technical PCN formulations, impurities in commercial PCB mixtures and other chemicals, and unintentional formation and emission from industrial thermal processes (Falandysz, 1998; Yamashita et al., 2000). Because of their chemical stability, flame resistance, and fungicidal and insecticidal properties, PCN formulations were used as capacitor fluids, engine oil additives, cable insulation additives, and for impregnating wood or paper. Approximately $150000 \mathrm{t}$ of PCNs were produced between 1910 and 1970, under trade names such as Clonacire Wax, Halowax, Nibren Wax, and Seekay Wax (Bogdal et al., 2006). It has been estimated that $169 \mathrm{t}$ of $\mathrm{PCN}$ have been released from the use of PCBs, based on concentrations of PCN impurities measured in technical PCB mixtures and global PCB production estimates (Yamashita et al., 2000). The manufacture of technical PCB mixtures has been banned across the world for decades, and many countries ceased manufacturing and using PCNs as industrial chemicals in the 1970s or 1980s (Hogarh et al., 2012). Currently, therefore, the emission of PCNs from their unintentional formation in industrial thermal processes could be much more important, relative to total emission, than previously. 
Table 1

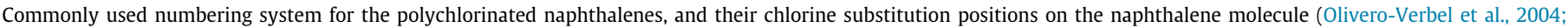
Kucklick and Helm, 2006).

\begin{tabular}{|c|c|c|c|c|c|c|c|c|c|}
\hline Number & Position & Number & Position & Number & Position & Number & Position & Number & Position \\
\hline MonoCN & & 15 & $1,2,5$ & 31 & $1,2,3,8$ & 48 & $2,3,6,7$ & HexaCN & \\
\hline 1 & 1 & 16 & $1,2,6$ & 32 & $1,2,4,5$ & & & 63 & $1,2,3,4,5,6$ \\
\hline 2 & 2 & 17 & $1,2,7$ & 33 & $1,2,4,6$ & PentaCN & & 64 & $1,2,3,4,5,7$ \\
\hline $\mathrm{DiCN}$ & & 18 & $1,2,8$ & 34 & $1,2,4,7$ & 49 & $1,2,3,4,5$ & 65 & $1,2,3,4,5,8$ \\
\hline 3 & 1,2 & 19 & $1,3,5$ & 35 & $1,2,4,8$ & 50 & $1,2,3,4,6$ & 66 & $1,2,3,4,6,7$ \\
\hline 4 & 1,3 & 20 & $1,3,6$ & 36 & $1,2,5,6$ & 51 & $1,2,3,5,6$ & 67 & $1,2,3,5,6,7$ \\
\hline 5 & 1,4 & 21 & $1,3,7$ & 37 & $1,2,5,7$ & 52 & $1,2,3,5,7$ & 68 & $1,2,3,5,6,8$ \\
\hline 6 & 1,5 & 22 & $1,3,8$ & 38 & $1,2,5,8$ & 53 & $1,2,3,5,8$ & 69 & $1,2,3,5,7,8$ \\
\hline 7 & 1,6 & 23 & $1,4,5$ & 39 & $1,2,6,7$ & 54 & $1,2,3,6,7$ & 70 & $1,2,3,6,7,8$ \\
\hline 8 & 1,7 & 24 & $1,4,6$ & 40 & $1,2,6,8$ & 55 & $1,2,3,6,8$ & 71 & $1,2,4,5,6,8$ \\
\hline 9 & 1,8 & 25 & $1,6,7$ & 41 & $1,2,7,8$ & 56 & $1,2,3,7,8$ & 72 & $1,2,4,5,7,8$ \\
\hline 10 & 2,3 & 26 & $2,3,6$ & 42 & $1,3,5,7$ & 57 & $1,2,4,5,6$ & & \\
\hline 11 & 2,6 & TetraCN & & 43 & $1,3,5,8$ & 58 & $1,2,4,5,7$ & HeptaCN & \\
\hline 12 & 2,7 & 27 & $1,2,3,4$ & 44 & $1,3,6,7$ & 59 & $1,2,4,5,8$ & 73 & $1,2,3,4,5,6,7$ \\
\hline TriCN & & 28 & $1,2,3,5$ & 45 & $1,3,6,8$ & 60 & $1,2,4,6,7$ & 74 & $1,2,3,4,5,6,8$ \\
\hline 13 & $1,2,3$ & 29 & $1,2,3,6$ & 46 & $1,4,5,8$ & 61 & $1,2,4,6,8$ & OctaCN & \\
\hline 14 & $1,2,4$ & 30 & $1,2,3,7$ & 47 & $1,4,6,7$ & 62 & $1,2,4,7,8$ & 75 & $1,2,3,4,5,6,7,8$ \\
\hline
\end{tabular}

Identifying and quantifying PCN emissions from various sources is one of the primary steps necessary for achieving source reductions. In this article, we will review and discuss the sampling and analysis of PCNs in emissions from thermal processes and the PCN formation mechanisms in these processes. The emission levels, emission profiles, and emission factors of PCNs from a number of industrial thermal processes are also summarized and compared, and these data will be useful in prioritizing source emission controls and for studying PCN source-receptor relationships.

\section{Sampling and analysis of PCNs released from thermal processes}

\subsection{Sampling techniques for stack gases from thermal processes}

There is currently no internationally authorized standard method for sampling PCNs in stack gases emitted from thermal processes. An automatic isokinetic sampling technique has been used to collect stack gas samples from waste incineration, coking, and secondary metal smelting processes (Oh et al., 2007; Ba et al., 2010; Liu et al., 2010) using a sampling train consisting of a heated probe, a filter box with a quartz fiber filter, a water-cooled XAD-2 adsorbent trap, a pump, and a cooler. The quartz fiber filter was used to collect particle-bound pollutants, and the XAD-2 adsorbent resin was used to trap the vapor-phase pollutants.

PCNs and similar compounds, such as PCDD/Fs, PCBs, and polyaromatic hydrocarbons (PAHs), can be produced as by-products during thermal processes (Takasuga et al., 2004; Oh et al., 2007; Nie et al., 2011; Nie et al., 2012a,b), so sampling and analyzing PCNs simultaneously with similar compounds would allow correlations between the chemical types to be studied and may help elucidate their formation mechanisms. Oh et al. (2007) suggested that automatic isokinetic sampling systems could be used for the simultaneous collection of PCDD/Fs, PCNs, and PAHs from waste incinerator stack gases, and such systems have been used to simultaneously collect several types of POPs from stack gases from primary and secondary metal smelting processes (Nie et al., 2011; Nie et al., 2012a,b).

Using these sampling methods, adding standards to the sampling media before sampling begins is very important for assessing the PCN sampling recoveries/efficiencies, and surrogate labeled standards, such as ${ }^{37} \mathrm{Cl}_{4}-2378$-TCDD, have been used as sampling standards in some studies because there are few commercially available isotopic labeled PCN congeners (Abad et al., 1999). As mentioned earlier, there is currently no internationally authorized standard PCN sampling method, but establishing a standard method for the simultaneous collection of PCNs and similar compounds would be valuable, and recent developments in this area have been very promising (Oh et al., 2007; Nie et al., 2011; Nie et al., 2012a,b).

\subsection{Analysis of PCNs in stack gas and fly ash samples}

Gas chromatography (GC) combined with mass spectrometry (MS) is the main current method that is used for PCN analysis (Weber et al., 2001; Kucklick and Helm, 2006; Guo et al., 2009), and GC combined with high resolution MS (GC/HRMS) is the optimum technique for the analysis of many trace organic pollutants in environmental matrices. GC/HRMS analysis of PCNs was first reported in the late 1990s (Schneider et al., 1998; Abad et al., 1999), but ${ }^{13} \mathrm{C}$-labeled PCB or ${ }^{13} \mathrm{C}$-labeled PCDD surrogate standards were used as internal standards for quantifying PCNs in those studies because no ${ }^{13} \mathrm{C}$-labeled $\mathrm{PCN}$ congeners were available at that time.

${ }^{13} \mathrm{C}$-labeled PCN standards were not commercially available until 2002 (Kucklick and Helm, 2006), and the first study using labeled PCN congeners as internal standards for PCN analysis using GC/HRMS was published in 2004 (Guruge et al., 2004). In 2008, Guo et al. reported an isotope dilution GC/HRMS method for the analysis of PCNs in sewage sludge (Guo et al., 2008), and isotope dilution GC/HRMS methods have recently been used to analyze PCNs in fly ash and stack gas samples from industrial thermal processes (Ba et al., 2010; Liu et al., 2010).

A typical analytical procedure for analyzing PCNs in stack gas or fly ash samples using isotope dilution GC/HRMS is briefly described next. Samples are spiked with known amounts of ${ }^{13} \mathrm{C}_{10}$-PCN internal standards (catalog No. ECN-5102, containing ${ }^{13} \mathrm{C}_{10}$-CNs 27, 42, 52, 67, 73, and 75; Cambridge Isotope Laboratories, Andover, MA, USA) and Soxhlet extracted for about $24 \mathrm{~h}$. The extracts are then concentrated in a rotary evaporator then cleaned up using multilayer silica gel and basic alumina chromatography columns. Finally, the eluted fractions are reduced to about $20 \mu \mathrm{L}$ by a rotary evaporator and a gentle stream of nitrogen, and a ${ }^{13} \mathrm{C}_{10}$-labeled PCN injection standard (catalog No. ECN-5260, containing ${ }^{13} \mathrm{C}_{10^{-}}$ CN 64; Cambridge Isotope Laboratories) added.

The sample extracts are then analyzed using a GC/HRMS instrument using a DB-5 fused silica capillary column $(60 \mathrm{~m}$ long, $0.25 \mathrm{~mm}$ i.d., $0.25 \mu \mathrm{m}$ film thickness; J\&W, Agilent Technologies Inc., USA) to separate the congeners. The HRMS is operated at around 10000 resolution and at $45 \mathrm{eV}$ electron energy, in electron impact ionization mode. Selected ion monitoring mode is used for the data acquisition, and the $\mathrm{m} / \mathrm{z}$ ratios that are monitored, and the 
theoretical isotopic ratios are compared and considered for the congener identification (Ba et al., 2010; Liu et al., 2010). Fewer than half of the 75 PCN congeners are commercially available, so the PCN congeners that can be used as analytical standards are very limited. Isotopic labeled PCN congeners are even more limited in their availability, with only seven ${ }^{13} \mathrm{C}$-labeled congeners currently being commercially available. The accurate identification and quantification of all 75 congeners has therefore proved difficult, and some uncertainty remains in the chromatographic identification of certain congeners (Helm and Bidleman, 2003). Peaks have been identified by comparing their retention times to those of available individual standards in many studies, and in some studies the PCN congener elution order on a DB-5 column has also been taken into account (Schneider et al., 1998; Abad et al., 1999). Congeners are identified and quantified only if the target/qualifier ion ratios are within $15 \%$ or $20 \%$ of the theoretical values. Quantifying PCN congeners has been achieved using an individual congener standard, selected from those available, to represent each homolog group, and using the same response factor for all of the congeners within each homolog group.

The congener specific analysis of PCNs remains challenging because of the very similar characteristics of some PCN congeners. For example, the complete separation of isomeric pentachlorinated and hexachlorinated naphthalenes, especially CNs 66 and 67, has been found to be very difficult (de Boer, 1999), and the complete separation of the pentachlorinated and hexachlorinated naphthalenes was first achieved using a GC equipped with a Rt-bDEXcst column in 1999 (Helm et al., 1999). Comprehensive two-dimensional gas chromatography $(\mathrm{GC} \times \mathrm{GC})$ has shown promise in the simultaneous analysis of several classes of halogenated organic compounds, including PCNs, PCBs, PCDD/Fs, organochlorine pesticides, and brominated flame retardants (Korytar et al., 2005).

\subsection{Quality control and quality assurance in PCN analysis}

Quality control and quality assurance $(\mathrm{QA} / \mathrm{QC})$ are very important when analyzing trace contaminants, and the limits of detection, recoveries, and blank control concentrations are the basic $\mathrm{QA} / \mathrm{QC}$ parameters. Interlaboratory comparison studies are also effective in assessing, and, to an extent, ensuring data quality, but there have been very few interlaboratory PCN analysis studies (in contrast with $\mathrm{PCDD} / \mathrm{F}$ analysis studies). Two interlaboratory studies, assessing analytical protocols for the analysis of PCNs in environmental matrices, have been conducted to determine the comparability of PCN data (Harner and Kucklick, 2003, 2005), with seven laboratories participating in one of the studies and nine in the other. The relative standard deviation (RSD) for the sum of the PCN concentrations was around $10 \%$ in these studies, but the RSDs for individual congeners were more variable, at $20-40 \%$.

In summary, although methodological enhancements in PCN analysis have been achieved, further advances are still needed in standard availability, chromatographic separations, and quality control to improve data produced from PCN studies in such fields as environmental monitoring and behavior, human exposure, and source identification and quantification.

\section{PCN formation mechanisms}

\subsection{PCN formation from PAHs and chlorophenols}

PCNs can be formed from aromatic organic precursors. PAHs are potential precursors for PCNs, and PCN formation mechanisms from PAHs, including perylene and benzo[ghi]perylene have been studied (Iino et al., 1999; Weber et al., 2001). In these studies, the PCN isomer patterns led the authors to suggest the potential
PCN formation pathways during waste incineration, from perylene and benzo[ghi]perylene. The formation of PCNs from chlorophenols has also been reported, and a PCN formation pathway building on the dihydrofulvalene-naphthalene mechanism has been proposed (Kim and Mulholland, 2005; Kim et al., 2005, 2007). In this mechanism, the phenoxy radical decomposes, through CO loss, to produce the cyclopentadienyl radical, which is resonance stabilized over all of its five carbon atoms, and cyclopentadienyl radicals combine and rearrange to form naphthalene. Similar mechanisms for the formation of PCDFs from chlorophenols have also been observed (Kim and Mulholland, 2005), and the overall reaction pathways that have been proposed for PCN and PCDF formation from chlorophenols are shown in Fig. S1 (Kim and Mulholland, 2005).

\subsection{Formation of more chlorinated PCN homologs by the chlorination of less chlorinated homologs}

Jansson et al. (2008) showed that injecting naphthalene into the post-combustion zone of a laboratory-scale fluidized-bed combustion reactor could increase the amount of monochlorinated naphthalenes, indicating that the chlorination of naphthalene was one of the PCN formation pathways. Two parallel chlorination pathways leading from monochlorinated to heptachlorinated naphthalenes were postulated, based on the isomer distribution patterns that were found.

Using correlation analysis to indicate interrelationships allowed an understanding of the mechanistic relationships between relevant chemicals to be gained (Oh et al., 2007), and adjacent PCN homolog groups were found to be closely related to each other using Pearson's correlation analysis. This suggests that the main PCN formation mechanism is likely to be related to chlorination and/or dechlorination in municipal waste incinerators. Pearson's correlation analysis of coking process samples showed that correlations between the dichlorinated and trichlorinated naphthalenes were stronger than the correlations between the dichlorinated naphthalenes and either the tetrachlorinated or pentachlorinated naphthalenes. The Pearson's correlations between the trichlorinated naphthalenes and either the tetrachlorinated or pentachlorinated naphthalenes were also higher than between the trichlorinated and hexachlorinated naphthalenes. The correlations between the tetrachlorinated and pentachlorinated naphthalenes were more significant than the correlations between the tetrachlorinated naphthalenes and the other highly chlorinated PCNs. The correlations between the hexachlorinated and heptachlorinated naphthalenes were stronger than the correlations between the hexachlorinated naphthalenes and octachlorinated naphthalene. In general, the correlations were stronger between adjacent PCN homologs than between non-adjacent homologs. The chlorination of less chlorinated homologs was, therefore, suggested as being one of the most important pathways for the formation of more chlorinated homologs in coking processes (Liu et al., 2010).

The proposed PCN formation mechanisms have not been accepted by all researchers in the field, however, and there is no international consensus on which are the major PCN formation mechanisms. Chlorination is widely regarded as being one of the major PCN formation pathways during waste combustion, but a recent study by Ryu et al. showed that PCN homolog and isomer patterns were clearly different from naphthalene chlorination experiments and from actual waste combustion (Ryu et al., 2013), leading the authors to suggest that chlorination is not a primary PCN formation route during waste combustion.

\subsection{Correlations between PCN formation with PCDD/F formation}

A strong correlation between PCN formation and PCDF formation in some thermal processes has been confirmed in a number 
of studies (Iino et al., 2001; Imagawa and Lee, 2001; Oh et al., 2007), and correlations between PCN and PCDF mass concentrations in stack gas samples from coking processes and waste incinerators have been studied (Liu et al., 2009, 2010), the results of which are shown in Fig. S2. There were very significant correlations between PCN and PCDF concentrations in samples from coking processes and waste incinerators, and the correlation coefficients $\left(R^{2}\right)$ were 0.65 for the coking processes and 0.72 for the waste incinerators.

Fly ash is considered to be an important matrix for the catalysis of heterogeneous reactions that lead to the formation of unintentionally produced POPs, because of the high carbon and catalytic element concentrations in fly ash (Schneider et al., 1998; Lin et al., 2011). Concentrations of unintentionally produced POPs in fly ash could represent the amounts of unintentionally produced POPs formed during a thermal process well. Liu et al. (2013) studied the correlations between PCN and PCDD/F concentrations in 36 fly ash samples from 20 thermal industry plants (waste incinerators and metallurgical facilities) and found significant correlations between PCN and PCDD/F concentrations. The correlation coefficients for the relationships between each of the tetrachlorinated, pentachlorinated, and hexachlorinated naphthalene homolog groups and each of the pentachlorodibenzofuran, hexachlorodibenzofuran, and hexachlorodibenzo- $p$-dioxin homolog groups were between 0.58 and 0.89 with an average of 0.74 , so the PCN and PCDD/F concentrations clearly correlated in samples from these thermal processes. These correlation analyses indicate that the PCNs and PCDFs had similar formation mechanisms. The potential PCN and PCDF formation pathways during thermal processes have been postulated, and are illustrated in Fig. 2, based on the studies that have been performed (Tuppurainen et al.,
1998; Iino et al., 1999; Weber et al., 2001; Tuppurainen et al., 2003; Kim and Mulholland, 2005; Kim et al., 2005, 2007). The black arrows in Fig. 2 represent common PCN and PCDF formation steps, the blue arrows indicate possible PCN formation pathways, and the red arrows indicate potential PCDF formation pathways, and de novo and precursor pathways are incorporated in the figure.

PCNs may be formed through similar de novo pathways as PCDFs. One pathway involves the complete oxidation of carbon residues to produce carbon monoxide and carbon dioxide, the formation of aliphatic precursors by the Fischer-Tropsch reaction. The aliphatic precursors are transformed into phenol by aromatization cyclization, and chlorination of phenol produces chlorophenol. PCNs can then be formed through a series of reactions of chlorophenol (Kim and Mulholland, 2005; Kim et al., 2005, 2007). Phenol can also be transformed into naphthalene (Kim et al., 2007), which can be chlorinated to form PCNs (Jansson et al., 2008; Liu et al., 2010). A secondary pathway involves the fragmentation of carbon residues producing naphthalene and other PAHs, then the chlorination of naphthalene and the decomposition and chlorination of other PAHs producing PCNs. A final pathway involves PCNs being produced by a series of reactions starting with the initial production of chlorophenol (Kim and Mulholland, 2005; Kim et al., 2005, 2007).

\section{PCN emissions from industries that use thermal processes}

\subsection{Concentrations and TEQs of PCN emissions from different industries}

The historic production of PCNs, their production as impurities in commercial PCB mixtures and other chemicals, and their

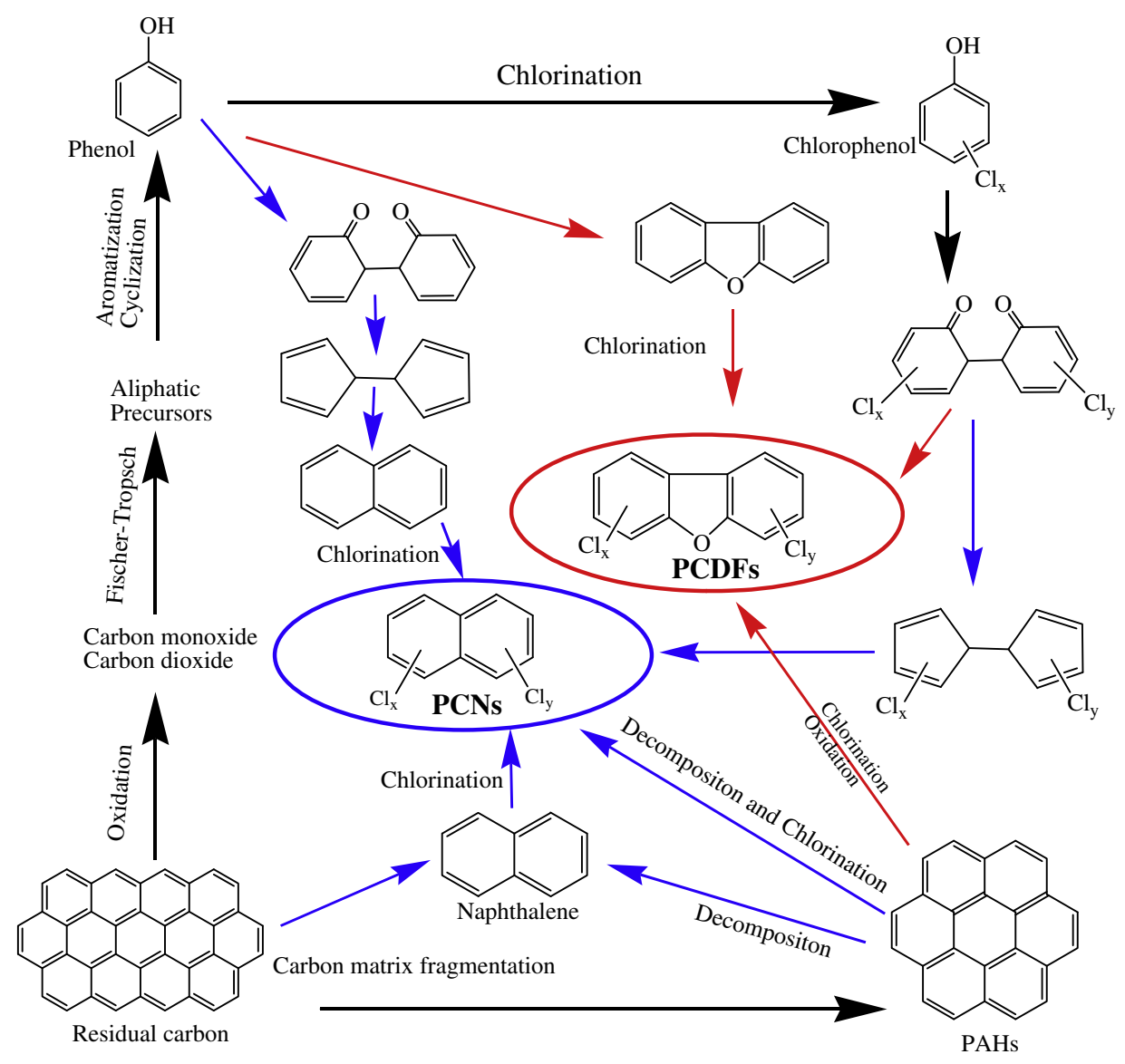

Fig. 2. Possible formation pathways for PCNs and PCDFs during thermal processes. 


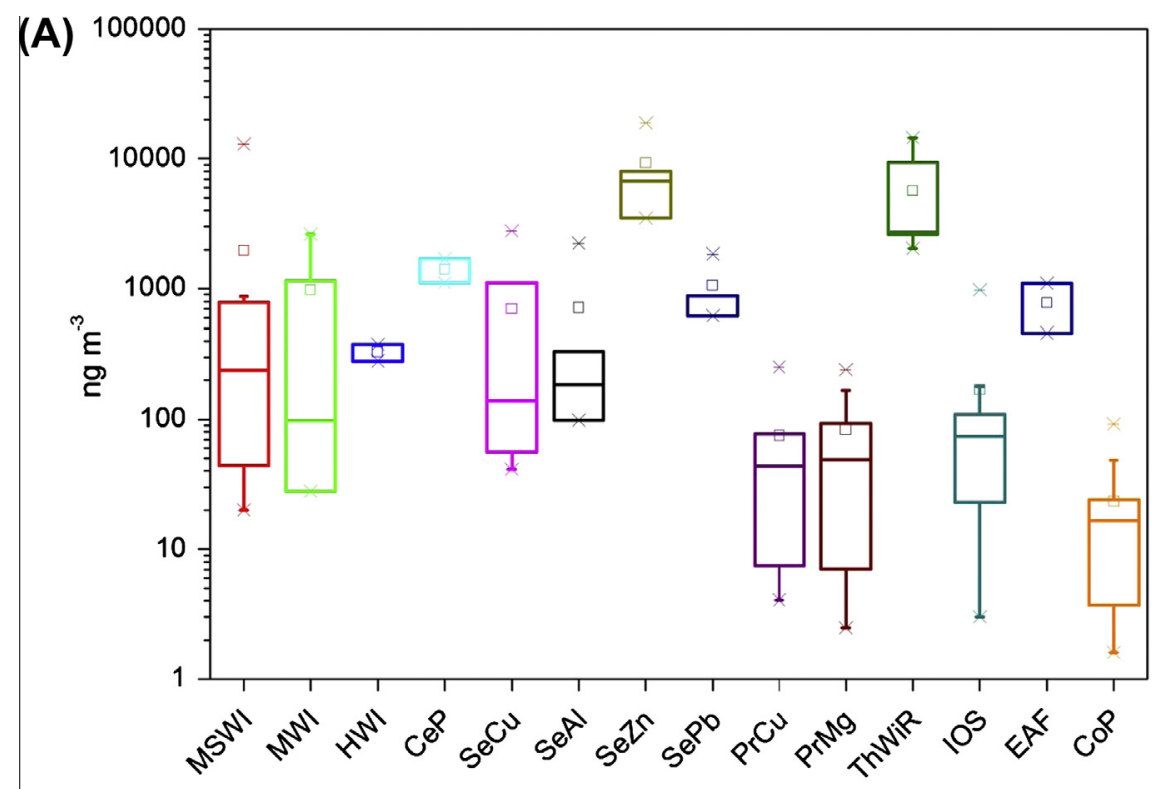

(B)

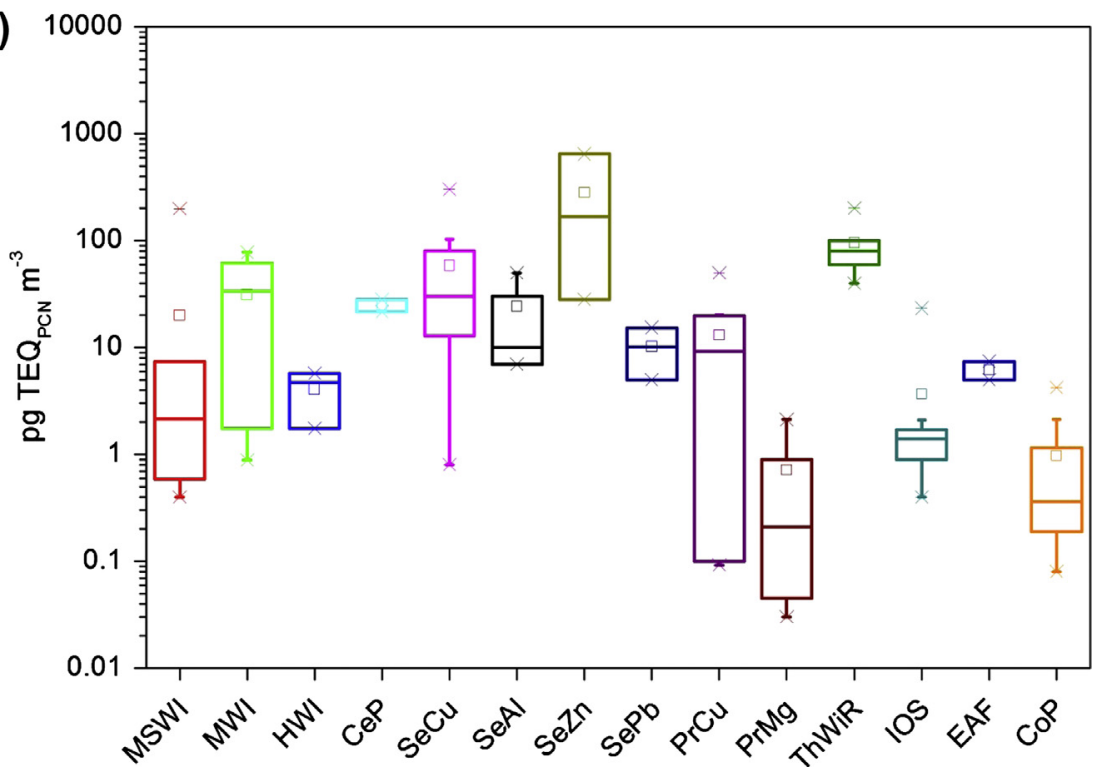

Fig. 3. Concentrations (A) and TEQs (B) of PCN emissions from a number of thermal processes.

unintentional formation and emission from industrial activities have been the major sources of PCNs (Falandysz, 1998; Yamashita et al., 2000; Noma et al., 2004). It has been speculated that the unintentional formation and emission of PCNs from industrial activities will become much more important than previously because the manufacture and use of PCNs and PCBs as industrial chemicals has ceased in many countries (Hogarh et al., 2012). PCN emissions have been investigated from a number of industrial thermal processes, including waste incineration (Takasuga et al., 2004; Noma et al., 2006; Sakai et al., 2006; Hu et al., 2012), iron and steel production (Liu et al., 2012a,b), nonferrous smelting processes (Sinkkonen et al., 2004; Nie et al., 2011; Nie et al., 2012a,b), coking industries (Liu et al., 2010), and cement production (Liu et al., 2011).

Comparing PCN emissions from industrial thermal processes could provide data that are useful for understanding environmental PCN burdens and the risks associated with exposure to PCNs around industrial plants. Comparing PCN emissions from various sources will also allow the prioritization of the implementation of source controls, to reduce PCN emissions using the best available technologies and best environmental practices. PCN emission concentrations and TEQs from fourteen thermal process sources are shown in Fig. 3. The PCN TEQs were calculated as the sum of the products of the concentrations of each congener and their RPFs (Noma et al., 2004; Guo et al., 2008). It can be seen from Fig. 3 that PCN emissions are significantly higher from secondary zinc smelting and thermal wire reclamation than from other processes, suggesting that controlling unintentional PCN emissions in these processes should be prioritized in China. The environmental PCN burden and risk from exposure to PCNs around industrial sources has been attracting increasing attention, and the data shown in Fig. 3 also suggest that the impact of PCN emissions from secondary zinc smelting and thermal wire reclamation plants on the surrounding environment and human health needs to be evaluated further.

The raw materials, specific techniques used in the plant, and end-of-stack treatments are the most important factors influencing the emission of unintentionally produced POPs from thermal pro- 

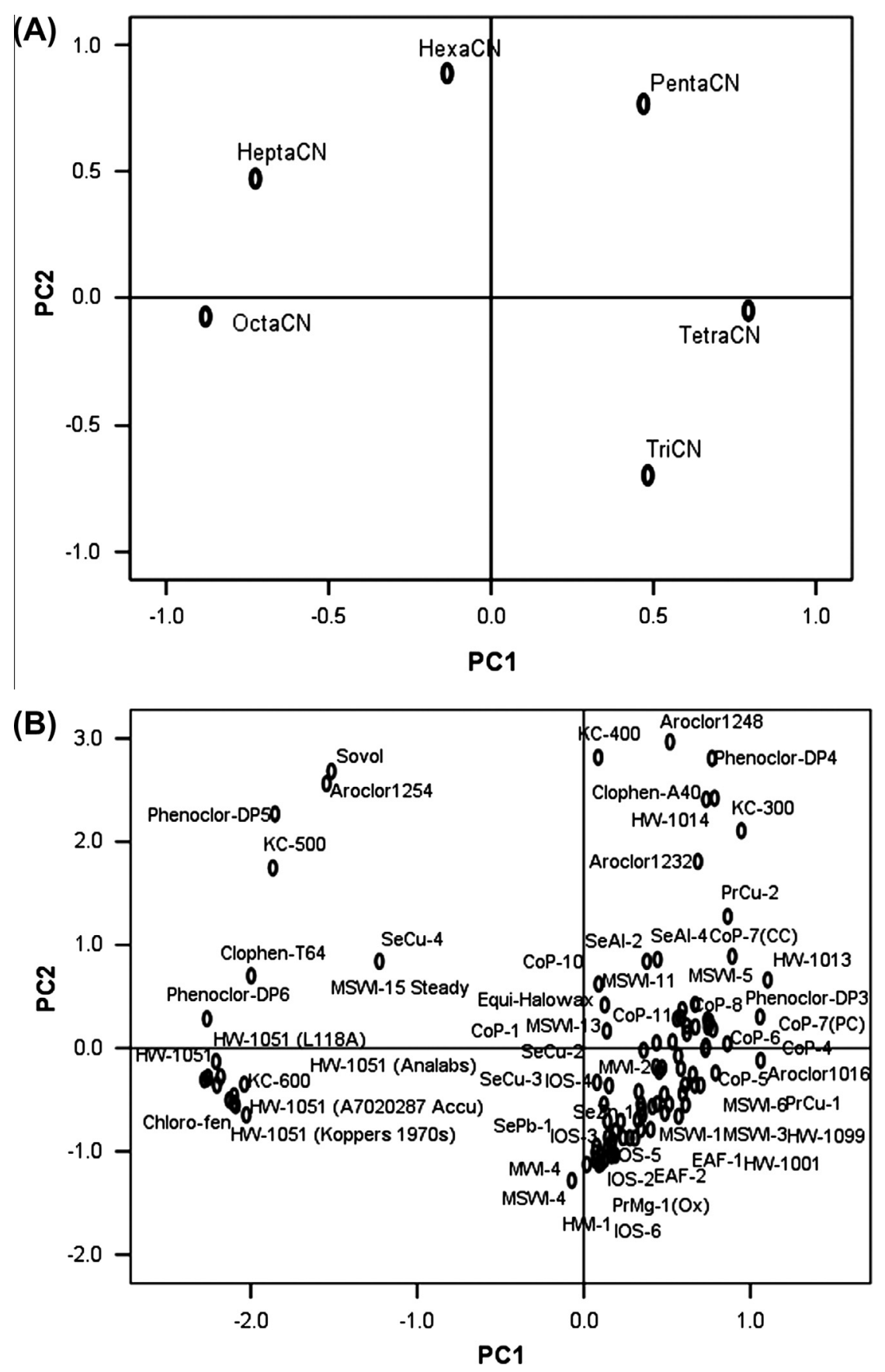

Fig. 4. Loading plot (A) and score plot (B) from the principal components analysis of the relative contributions of PCN homologs in different PCN sources.

cesses (Tuppurainen et al., 1998; Stanmore, 2004; Aries et al. 2006). Studying the effects of key factors on PCN emissions could allow significant reductions in PCN emissions from thermal processes to be made. PCN emission concentrations vary to a tremendous extent between different operational stages in waste incinerators (Falandysz, 1998), with PCN concentrations of 15000,4300 , and $13000 \mathrm{ng} \mathrm{m}^{-3}$ having been found in flue gas samples collected during startup, steady operation, and shutdown conditions, respectively. PCN concentrations of 470,370 , and $1400 \mathrm{ng} \mathrm{g}^{-1}$ have been found in fly ash during startup, steady operation, and shutdown conditions, respectively (Takasuga et al., 2004). In these studies, much higher PCN emissions were found under startup and shutdown conditions than under steady operation conditions (Falandysz, 1998; Takasuga et al., 2004). PCN emis- sions during the startup and shutdown of waste incinerators should not, therefore, be ignored, and should, perhaps, even be prioritized. The composition of the raw materials used in thermal processes may affect the PCN emissions, and studies have shown that increasing the amount of recycled materials used leads to increased emissions of PCNs and dioxins from iron ore sintering processes (Xhrouet and De Pauw, 2004; Liu et al., 2012b).

\subsection{Homolog distributions and congener profiles in PCN emissions}

PCN profiles from various industrial sources could provide helpful information for (1) speculating on the PCN formation mechanisms (Oh et al., 2007; Jansson et al., 2008; Liu et al., 2010; Jansson and Andersson, 2012), and (2) identifying specific PCN 
(A)

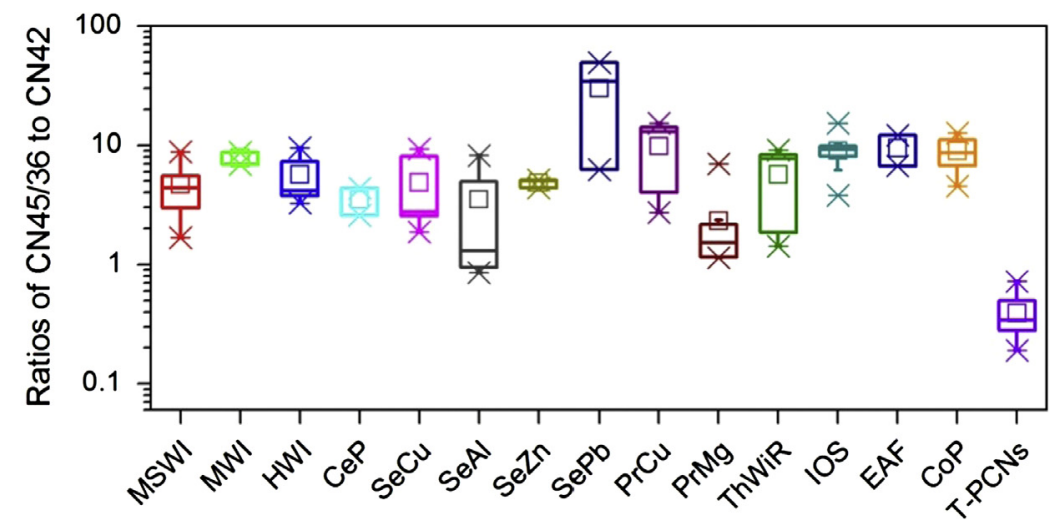

(B)

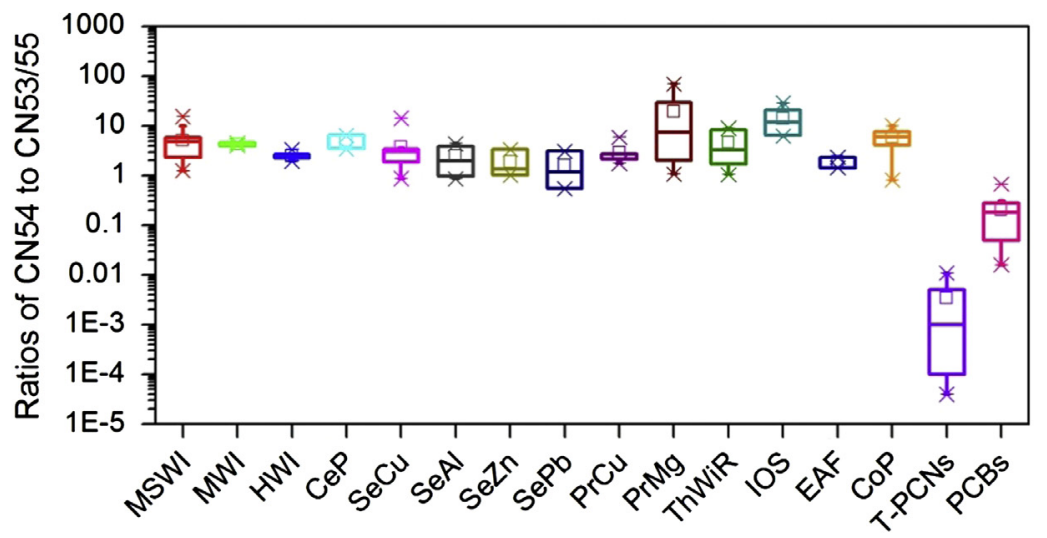

(C)

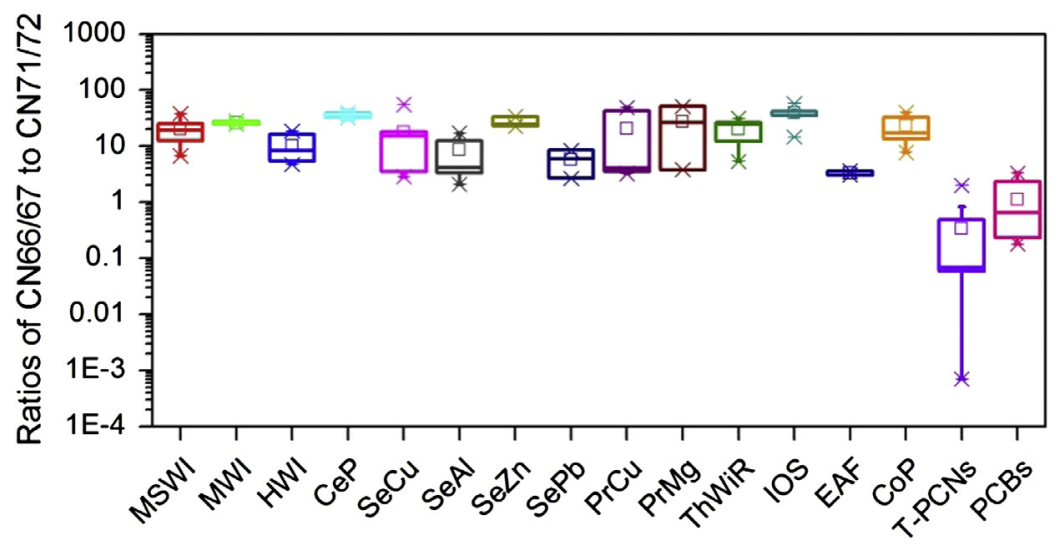

(D)

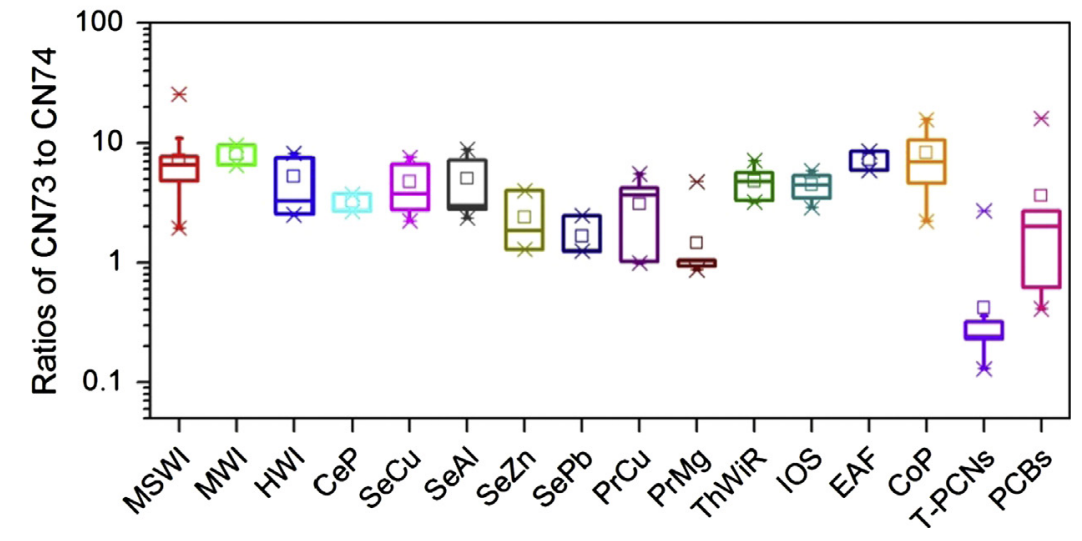

Fig. 5. Ratios of characteristic PCN congeners in different PCN sources. T-PCNs: technical PCN formulations; PCBs: technical PCB formulations. 
Table 2

PCN emission factors to the atmosphere from industrial thermal sources.

\begin{tabular}{|c|c|c|c|c|c|}
\hline Sources & Denotation & $\begin{array}{l}\text { Emission factor in } \\
\text { concentration }\left(\mu \mathrm{g} \mathrm{t}^{-1}\right)\end{array}$ & $\begin{array}{l}\text { Emission factor in TEQ } \\
\left(\mathrm{ng} \mathrm{TEQ}^{-1}\right)\end{array}$ & $\begin{array}{l}\text { Annual emission estimates } \\
\text { (mg TEQ) }\end{array}$ & References \\
\hline Iron ore sintering & IOS & $14-1749(84)^{\mathrm{a}}$ & $0.5-41.5(2.1)$ & 1390 & Liu et al. (2012d) \\
\hline Electric arc furnace & EAF & $1970-4475(3223)$ & $21.6-30.1(25.9)$ & $\mathrm{NA}^{\mathrm{b}}$ & Liu et al. (2012c) \\
\hline Cement kiln & $\mathrm{CeP}^{\mathrm{c}}$ & 242 & 3.7 & NA & Liu et al. (2011) \\
\hline Secondary copper smelting & $\mathrm{SeCu}$ & $141-9154(2666)$ & $2.8-1989$ (349) & 860 & $\begin{array}{l}\text { Ba et al. (2010), Nie et al. } \\
\text { (2012a) }\end{array}$ \\
\hline $\begin{array}{l}\text { Secondary aluminum } \\
\text { smelting }\end{array}$ & SeAl & $575-13610(4082)$ & $33.8-316(143)$ & 390 & Ba et al. (2010) \\
\hline Secondary zinc smelting & SeZn & 3431 & 126 & 10 & Ba et al. (2010) \\
\hline Secondary lead smelting & $\mathrm{SePb}$ & 1336 & 20.1 & 9 & Ba et al. (2010) \\
\hline Primary copper smelting & $\mathrm{PrCu}$ & $11.2-69.0$ & $0.2-13.0$ & NA & Nie et al. (2012a) \\
\hline $\begin{array}{l}\text { Primary magnesium } \\
\text { smelting }\end{array}$ & PrMg & 3329 & 32.1 & 16.1 & Nie et al. (2011b) \\
\hline Coking process & $\mathrm{CoP}$ & $5.1-50.3$ & $0.77-1.24$ & 430-692 (global) & Liu et al. (2010) \\
\hline Thermal wire reclamation & ThWiR & $2715-8650$ & $90-100$ & NA & Nie et al. (2012b) \\
\hline $\begin{array}{l}\text { Municipal solid waste } \\
\text { incineration }\end{array}$ & MSWI & $71-53253(8503)$ & $1.4-810(150)$ & NA & Guo et al. (2008) \\
\hline Medical waste incineration & MWI & 981 & 17 & NA & Guo et al. (2008) \\
\hline $\begin{array}{l}\text { Hazardous waste } \\
\text { incineration }\end{array}$ & HWI & $269-5763(3016)$ & $5.4-27(16.2)$ & NA & Guo et al. (2008) \\
\hline
\end{tabular}

a Data in parentheses are the mean values.

b Not available.

c PCNs from the tetra- to the octa- homologs.

sources in industries that use thermal processes, or evaporative releases from historical uses of industrial chemicals (such as Halowaxes) (Jarnberg et al., 1997; Harner et al., 1998; Hanari et al., 2004; Schuhmacher et al., 2004; Gewurtz et al., 2009). The PCN concentrations and profiles in technical PCB and PCN formulations have been reported in detail (Falandysz et al., 2000; Yamashita et al., 2000; Noma et al., 2004; Falandysz et al., 2006a,b; Falandysz, 2007; Falandysz et al., 2008).

We used multivariate statistical analysis, specifically principal component analysis (PCA), to evaluate the PCN patterns and to identify possible groupings with similar emission characteristics. The PCN homolog concentrations were normalized to the total PCN concentrations to minimize the influence of the total concentration and to allow compositional similarities among samples to be assessed. PCA was performed using SPSS 13.0 for Windows, using a varimax rotation method. The loading plot $(A)$ and score plot (B) for the relative contributions of the PCN homologs are presented in Fig. 4, and it can be seen from Fig. 4B that the less chlorinated PCN homologs (trichlorinated and tetrachlorinated naphthalenes) were the dominant homologs emitted from industrial thermal sources. However, for most of the technical PCN mixtures (such as the Halowaxes, except for HW-1014), the octachlorinated naphthalene fraction was the highest. The pentachlorinated and hexachlorinated naphthalenes were the dominant homologs in the commercial PCB mixtures that were produced in the past, including Aroclor1248, Aroclor1232, Clophen-A40, KC300, KC-400, and Phenoclor-DP4.

The PCN congener profiles emitted from thermal processes and present in technical PCN mixtures have been compared in a number of studies (Jarnberg et al., 1999; Ishaq et al., 2003, 2009). Several congeners, including CNs 45/36, CN 54, CNs 66/67, and CN 73 have been widely recognized as being indicators of PCN emissions from thermal processes, because they are relatively abundant in emissions from thermal processes, but are present at much lower concentrations in Halowax mixtures (Meijer et al., 2001; Helm and Bidleman, 2003). We have summarized the ratios of several characteristic congeners in Fig. 5, and it can be seen that the ratios of the congeners that are associated with thermal processes varied only to a limited extent in emissions from industrial thermal sources, but varied strongly between the industrial thermal sources, the technical PCN mixtures, and the technical PCB mixtures. These congener profiles could, therefore, provide useful information for identifying specific PCN sources (i.e., emissions from industries that use thermal processes or evaporative emissions from the historical use of industrial chemicals or technical PCB mixtures).

\subsection{PCN emission factors and emission estimates}

Emission factors are important parameters for estimating emissions of pollutants based on limited data. The United Nations Environment Programme has developed an emission factor toolkit for identifying and quantifying PCDD/Fs. Global, and some regional, $\mathrm{PCDD} / \mathrm{F}$ inventories have been developed. PCN emission factors for various sources could be useful for developing an emission inventory and prioritizing PCN sources for control measures.

An estimated $150000 \mathrm{t}$ of PCNs were produced between 1910 and 1970 under trade names such as Clonacire Wax, Halowax, Nibren Wax, and Seekay Wax (Bogdal et al., 2006). PCN emission factors for commercial PCB mixtures ranged from 39 to $730 \mathrm{mg} \mathrm{kg}^{-1}$ for different technical PCB mixtures (Yamashita et al., 2000), and the estimated total emission of PCNs from technical PCB production was $169375 \mathrm{~kg}$.

Although many case studies of PCN emissions from industrial processes have been performed (Ba et al., 2010; Liu et al., 2010, 2011; Nie et al., 2011; Hu et al., 2012; Liu et al., 2012c, Liu et al., 2012d, Nie et al., 2012a,b), a comprehensive summary of PCN emission factors from industrial thermal sources has not been produced. We have summarized the PCN emission factors and annual emissions from fourteen industrial thermal processes (metallurgical processes, combustion processes, and mineral product production) in Table 2. It could be seen from Table 2 that, the emission factors of PCNs for electric arc furnace, secondary copper smelting, secondary aluminum smelting, secondary zinc smelting, and thermal wire reclamation and waste incinerations were relatively higher than that of other industrial thermal sources. A wide data range of the mass emission factors of PCNs was observed for municipal solid waste incinerations (MSWI), which indicating the great difference in the emission controlling techniques of MSWI. While for cement kiln, secondary zinc smelting, secondary lead smelting, 
primary magnesium smelting and thermal wire reclamation, much more intensive investigations on PCN emissions might be essential for establishing an integrate inventory. Generally speaking, these data shown in Table 2 will be useful in preliminary evaluations of PCN emissions from industrial sources.

\section{Conclusions and perspectives}

This study provides a brief overview of recent progress in research into the unintentional production and emission of PCNs from a number of industrial thermal processes. Methods for sampling and analyzing PCNs, and PCN formation mechanism during thermal processes, have been summarized and discussed. Emission concentrations, emission profiles, and emission factors of PCNs from a number of industrial thermal sources have been summarized and compared.

There is currently no international consensus on standard sampling and analytical methods for PCNs, so international intercalibration studies of PCN sampling and analysis methods for industrial thermal sources are urgently required to allow comparable monitoring data to be acquired in the future. Much more intensive field monitoring of PCN emissions from industrial sources is also needed, so PCN emissions can be evaluated accurately. Further study of the PCN formation mechanisms and ways of reducing the amount of PCNs produced needs to be carried out, so that PCN source control measures can be implemented.

\section{Acknowledgements}

We gratefully acknowledge support from the Hong Kong Scholars Program (XJ2012055), and the National Natural Science Foundation of China (Nos. 21037003 and 21107123) and CAS (YSW2013B01).

\section{Appendix A. Supplementary material}

Supplementary data associated with this article can be found, in the online version, at http://dx.doi.org/10.1016/j.chemosphere. 2013.09.021.

\section{References}

Abad, E., Caixach, J., Rivera, J., 1999. Dioxin like compounds from municipal waste incinerator emissions: assessment of the presence of polychlorinated naphthalenes. Chemosphere 38, 109-120.

Aries, E., Anderson, D.R., Fisher, R., Fray, T.A.T., Hemfrey, D., 2006. PCDD/F and "dioxin-like" PCB emissions from iron ore sintering plants in the UK. Chemosphere 65, 1470-1480.

Ba, T., Zheng, M.H., Zhang, B., Liu, W.B., Su, G.J., Liu, G.R., Xiao, K., 2010. Estimation and congener-specific characterization of polychlorinated naphthalene emissions from secondary nonferrous metallurgical facilities in China. Environ. Sci. Technol. 44, 2441-2446.

Behnisch, P.A., Hosoe, K., Sakai, S., 2003. Brominated dioxin-like compounds: in vitro assessment in comparison to classical dioxin-like compounds and other polyaromatic compounds. Environ. Int. 29, 861-877.

Bidleman, T.F., Helm, P.A., Braune, B.M., Gabrielsen, G.W., 2010. Polychlorinated naphthalenes in polar environments - a review. Sci. Total Environ. 408, 29192935.

Blankenship, A.L., Kannan, K., Villalobos, S.A., Villeneuve, D.L., Falandysz, J., Imagawa, T., Jakobsson, E., Giesy, J.P., 2000. Relative potencies of individual polychlorinated naphthalenes and halowax mixtures to induce Ah receptormediated responses. Environ. Sci. Technol. 34, 3153-3158.

Bogdal, C., Kohler, M., Schmid, P., Sturm, M., Grieder, E., Scheringer, M.K.H., 2006. Polychlorinated naphthalenes: congener specific analysis and source identification in a dated sediment core from Lake Thun, Switzerland. Organohal. Compd. 68, 300-303.

de Boer, J., 1999. Capillary gas chromatography for the determination of halogenated micro-contaminants. J. Chromatogr. A 843, 179-198.

Domingo, J.L., 2004. Polychlorinated naphthalenes in animal aquatic species and human exposure through the diet: a review. J. Chromatogr. A 1054, 327-334.

Falandysz, J., 1998. Polychlorinated naphthalenes: an environmental update. Environ. Pollut. 101, 77-90.
Falandysz, J., 2003. Chloronaphthalenes as food-chain contaminants: a review. Food Addit. Contam. 20, 995-1014.

Falandysz, J., 2007. Dioxin-like compound load in bulk of chlorofen - a technical chlorobiphenyl formulation from Poland. J. Environ. Sci. Heal. A 42, 1959-1968.

Falandysz, J., Strandberg, B., Strandberg, L., Bergqvist, P.A., Rappe, C., 1997. Concentrations and biomagnification of polychlorinated naphthalenes in black cormorants Phalacrocorax carbo sinensis from the Gulf of Gdansk, Baltic Sea. Sci. Total Environ. 204, 97-106.

Falandysz, J., Kawano, M., Ueda, M., Matsuda, M., Kannan, K., Giesy, J.P., Wakimoto, T., 2000. Composition of chloronaphthalene congeners in technical chloronaphthalene formulations of the Halowax series. J. Environ. Sci. Heal. A 35, 281-298.

Falandysz, J., Nose, K., Ishikawa, Y., Lukaszewicz, E., Yamashita, N., Noma, Y., 2006a. Chloronaphthalenes composition of several batches of Halowax 1051. J. Environ. Sci. Heal. A 41, 291-301.

Falandysz, J., Nose, K., Ishikawa, Y., Lukaszewicz, E., Yamashita, N., Noma, Y., 2006b. HRGC/HRMS analysis of chloronaphthalenes in several batches of Halowax 1000, 1001, 1013, 1014 and 1099. J. Environ. Sci. Heal. A 41, 2237-2255.

Falandysz, J., Chudzynski, K., Takekuma, M., Yamamoto, T., Noma, Y., Hanari, N., Yamashita, N., 2008. Multivariate analysis of identity of imported technical PCN formulation. J. Environ. Sci. Heal. A 43, 1381-1390.

Fernandes, A., Mortimer, D., Gem, M., Smith, F., Rose, M., Penton, S., Carr, M., 2010. Polychlorinated naphthalenes (PCNs): congener specific analysis, occurrence in food, and dietary exposure in the UK. Environ. Sci. Technol. 44, 3533-3538.

Gewurtz, S.B., Lega, R., Crozier, P.W., Whittle, D.M., Fayez, L., Reiner, E.J., Helm, P.A. Marvin, C.H., Tomy, G.T., 2009. Factors influencing trends of polychlorinated naphthalenes and other dioxin-like compounds in lake Trout (Salvelinus Namaycush) from Lake Ontario, North America (1979-2004). Environ. Toxicol. Chem. 28, 921-930.

Guo, L., Zhang, B., Xiao, K., Zhang, Q.H., Zheng, M.H., 2008. Levels and distributions of polychlorinated naphthalenes in sewage sludge of urban wastewater treatment plants. Chin. Sci. Bull. 53, 508-513.

Guo, L., Ba, T., Zheng, M., 2009. Study of sources and distribution characteristics of polychlorinated naphthalenes. Prog. Chem. 21, 377-388.

Guruge, K.S., Seike, N., Yamanaka, N., Miyazaki, S., 2004. Accumulation of polychlorinated naphthalenes in domestic animal related samples. J. Environ. Monit. 6, 753-757.

Hanari, N., Horii, Y., Okazawa, T., Falandysz, J., Bochentin, I., Orlikowska, A., Puzyn T., Wyrzykowska, B., Yamashita, N., 2004. Dioxin-like compounds in pine needles around Tokyo Bay, Japan in 1999. J. Environ. Monit. 6, 305-312.

Hanberg, A., Waern, F., Asplund, L., Haglund, E., Safe, S., 1990. Swedish dioxin survey determination of 2,3,7,8-Tcdd toxic equivalent factors for some polychlorinated-biphenyls and naphthalenes using biological tests. Chemosphere 20, 1161-1164.

Harner, T., Kucklick, J., 2003. Interlaboratory study for the polychlorinated naphthalenes (PCNs): phase 1 results. Chemosphere 51, 555-562.

Harner, T. Kucklick, J. 2005. Interlaboratory study for the polychlorinated naphthalenes (PCNs): phase II results. Organohal. Compd. 67, 712-714.

Harner, T., Kylin, H., Bidleman, T.F., Halsall, C., Strachan, W.M.J., 1998. Polychlorinated naphthalenes and coplanar polychlorinated biphenyls in arctic air. Environ. Sci. Technol. 32, 3257-3265.

Helm, P.A., Bidleman, T.F., 2003. Current combustion-related sources contribute to polychlorinated naphthalene and dioxin-like polychlorinated biphenyl levels and profiles in air in Toronto, Canada. Environ. Sci. Technol. 37, 1075-1082.

Helm, P.A., Jantunen, L.M.M., Bidleman, T.F., Dorman, F.L., 1999. Complete separation of isomeric penta- and hexachloronaphthalenes by capillary gas chromatography. J. High. Resolut. Chromatogr. 22, 639-643.

Helm, P.A., Jantunen, L.M., Ridal, J., Bidleman, T.F., 2003. Spatial distribution of polychlorinated naphthalenes in air over the great lakes and air-water gas exchange in Lake Ontario. Environ. Toxicol. Chem. 22, 1937-1944.

Helm, P.A., Bidleman, T.F., Li, H.H., Fellin, P., 2004. Seasonal and spatial variation of polychlorinated naphthalenes and non-/mono-ortho-substituted polychlorinated biphenyls in arctic air. Environ. Sci. Technol. 38, 5514-5521.

Herbert, B.M.J., Halsall, C.J., Villa, S., Fitzpatrick, L., Jones, K.C., Lee, R.G.M., Kallenborn, R., 2005. Polychlorinated naphthalenes in air and snow in the Norwegian Arctic: a local source or an Eastern Arctic phenomenon? Sci. Total Environ. 342, 145-160.

Hogarh, J.N., Seike, N., Kobara, Y., Masunaga, S., 2012. Atmospheric polychlorinated naphthalenes in Ghana. Environ. Sci. Technol. 46, 2600-2606.

Hootha, M.J., Nyskab, A., Fombyc, L.M., Vasconcelosc, D.Y., Vallanta, M., DeVitoa, M.J., Walkera, N.J., 2012. Repeateddosetoxicity and relative potency of 1,2,3,4,6,7-hexachloronaphthalene $\quad$ (PCN 66) 1,2,3,5,6,7hexachloronaphthalene (PCN 67) compared to 2,3,7,8-tetrachlorodibenzo-pdioxin (TCDD) for induction of CYP1A1, CYP1A2 and thymic atrophy in female Harlan Sprague-Dawley rats. Toxicology 301, 85-93.

Horii, Y., Jiang, Q.T., Hanari, N., Lam, P.K.S., Yamashita, N., Jansing, R., Aldous, K.M., Mauer, M.P., Eadon, G.A., Kannan, K., 2010. Polychlorinated dibenzo-pdioxins, dibenzofurans, biphenyls, and naphthalenes in plasma of workers deployed at the world trade center after the collapse. Environ. Sci. Technol. 44, 5188-5194.

Hu, J.C., Zheng, M.H., Liu, W.B., Li, C.L., Nie, Z.Q., Liu, G.R., Zhang, B., Xiao, K., Gao, L.R. 2012. Characterization of polychlorinated naphthalenes in stack gas emissions from waste incinerators. Environ. Sci. Pollut. Res.. http://dx.doi.org/10.1007/ s11356-11012-11218-11350.

Iino, F., Imagawa, T., Takeuchi, M., Sadakata, M., 1999. De novo synthesis mechanism of polychlorinated dibenzofurans from polycyclic aromatic 
hydrocarbons and the characteristic isomers of polychlorinated naphthalenes. Environ. Sci. Technol. 33, 1038-1043.

Iino, F., Tsuchiya, K., Imagawa, T., Gullett, B.K., 2001. An isomer prediction model for PCNs, PCDD/Fs, and PCBs from municipal waste incinerators. Environ. Sci. Technol. 35, 3175-3181.

Imagawa, T., Lee, C.W., 2001. Correlation of polychlorinated naphthalenes with polychlorinated dibenzofurans formed from waste incineration. Chemosphere $44,1511-1520$

Ishaq, R., Naf, C., Zebuhr, Y., Broman, D., Jarnberg, U., 2003. PCBs, PCNs, PCDD/Fs, PAHs and Cl-PAHs in air and water particulate samples - patterns and variations. Chemosphere 50, 1131-1150.

Ishaq, R., Persson, N.J., Zebuhr, Y., Broman, D., Naes, K., 2009. PCNs, PCDD/Fs, and non-orthoPCBs, in water and bottom sediments from the industrialized Norwegian Grenlandsfjords. Environ. Sci. Technol. 43, 3442-3447.

ansson, S., Andersson, P.L., 2012. Relationships between congener distribution patterns of PCDDs, PCDFs, PCNs, PCBs, PCBzs and PCPhs formed during flue gas cooling. Sci. Total Environ. 416, 269-275.

Jansson, S., Fick, J., Marklund, S., 2008. Formation and chlorination of polychlorinated naphthalenes (PCNs) in the post-combustion zone during MSW combustion. Chemosphere 72, 1138-1144.

Jarnberg, U., Asplund, L., deWit, C., Egeback, A.L., Wideqvist, U., Jakobsson, E., 1997. Distribution of polychlorinated naphthalene congeners in environmental an source-related samples, Arch. Environ. Contam. Toxicol. 32, 232-245.

Jarnberg, U.G., Asplund, L.T., Egeback, A.L., Jansson, B., Unger, M., Wideqvist, U., 1999. Polychlorinated naphthalene congener profiles in background sediments compared to a degraded Halowax 1014 technical mixture. Environ. Sci. Technol. 33, 1-6.

Jaward, F.M., Farrar, N.J., Harner, T., Sweetman, A.J., Jones, K.C., 2004. Passive air sampling of polycyclic aromatic hydrocarbons and polychlorinated naphthalenes across Europe. Environ. Toxicol. Chem. 23, 1355-1364.

Kannan, K., Imagawa, T., Blankenship, A.L., Giesy, J.P., 1998. Isomer-specific analysis and toxic evaluation of polychlorinated naphthalenes in soil, sediment, an biota collected near the site of a former chlor-alkali plant. Environ. Sci. Technol. $32,2507-2514$

Kannan, K., Yamashita, N., Imagawa, T., Decoen, W., Khim, J.S., Day, R.M., Summer C.L., Giesy, J.P., 2000. Polychlorinated naphthalenes and polychlorinated Ciphenyls in fishes from Michigan waters including the Great Lakes. Environ. Sci. Technol. 34, 566-572.

Kannan, K., Kober, J.L., Kang, Y.S., Masunaga, S., Nakanishi, J., Ostaszewski, A., Giesy, J.P., 2001. Polychlorinated naphthalenes, biphenyls, dibenzo-p-dioxins, and dibenzofurans as well as polycyclic aromatic hydrocarbons and alkylphenols in sediment from the Detroit and Rouge Rivers, Michigan, USA. Environ. Toxicol. Chem. 20, 1878-1889.

Kilanowicz, A. Skrzypinska-Gawrysiak, M. 2010. Toxicity of hexachloronaphthalene $(\mathrm{HxCN})$ and induction of CYP $1 \mathrm{~A}$ in rats. Ecotox. Environ. Safe 73, 196-205.

Kilanowicz, A., Sitarek, K., Skrzypinska-Gawrysiak, M., Sapota, A., 2011. Prenata developmental toxicity of polychlorinated naphthalenes (PCNs) in the rat. Ecotox. Environ. Safe 74, 504-512.

Kilanowicz, A., Wiaderna, D., Lutz, P., Szymczak, W., 2012. Behavioral effects following repeated exposure to hexachloronaphthalene in rats. Neurotoxicology 33, 361-369.

Kim, D.H., Mulholland, J.A., 2005. Temperature-dependent formation of polychlorinated naphthalenes and dihenzofurans from chlorophenols. Environ. Sci. Technol. 39, 5831-5836.

Kim, D.H., Mulholland, J.A., Ryu, J.Y., 2005. Formation of polychlorinated naphthalenes from chlorophenols. Proc. Combust. Inst. 30, 1245-1253.

Kim, D.H., Mulholland, J.A., Ryu, J.Y., 2007. Chlorinated naphthalene formation from the oxidation of dichlorophenols. Chemosphere 67, S135-S143.

Korytar, P., Leonards, P.E.G., de Boer, J., Brinkman, U.A.T., 2005. Group separation of organohalogenated compounds by means of comprehensive two-dimensional gas chromatography. J. Chromatogr. A 1086, 29-44.

Krauss, M., Wilcke, W., 2003. Polychlorinated naphthalenes in urban soils: analysis concentrations, and relation to other persistent organic pollutants. Environ. Pollut. 122, 75-89.

Kucklick, J.R., Helm, P.A., 2006. Advances in the environmental analysis of polychlorinated naphthalenes and toxaphene. Anal. Bioanal. Chem. 386, 819836.

Lee, S.C., Harner, T., Pozo, K., Shoeib, M., Wania, F., Muir, D.C.G., Barrie, L.A., Jones, K.C., 2007. Polychlorinated naphthalenes in the global atmospheric passive sampling (GAPS) study. Environ. Sci. Technol. 41, 2680-2687.

Lerche, D., van de Plassche, E., Schwegler, A., Balk, F., 2002. Selecting chemica substances for the UN-ECE POP protocol. Chemosphere 47, 617-630.

Lin, C., Chin, Y.T., Chang-Chien, G.P., Wang, Y.M., 2011. PCDD/Fs formation catalyzed by the copper chloride in the fly ash. J. Environ. Sci. Heal. A 46, 465-470.

Liu, G.R., Zheng, M.H., Liu, W.B., Wang, C.Z., Zhang, B., Gao, L.R., Su, G.J., Xiao, K., Lv, P., 2009. Atmospheric emission of PCDD/Fs, PCBs, hexachlorobenzene, and pentachlorobenzene from the coking industry. Environ. Sci. Technol. 43, $9196-$ 9201.

Liu, G.R., Zheng, M.H., Lv, P., Liu, W.B., Wang, C.Z., Zhang, B., Xiao, K., 2010. Estimation and characterization of polychlorinated naphthalene emission from coking industries. Environ. Sci. Technol. 44, 8156-8161.

Liu, G.R., Zheng, M.H., Nie, Z.Q., Li, C., Zhang, B., Liu, W.B., Hu, J.C., 2011. Charactering the emission of polychlorinated naphthalenes from cement kiln. Organohal. Compd. 73, 62-65.
Liu, G., Zheng, M., Du, B., Nie, Z., Zhang, B., Hu, J., Xiao, K., 2012a. Identification and characterization of the atmospheric emission of polychlorinated naphthalenes from electric arc furnaces. Environ. Sci. Pollut. Res. 19, 3645-3650.

Liu, G., Zheng, M., Du, B., Nie, Z., Zhang, B., Liu, W., Li, C., Hu, J., 2012b. Atmospheric emission of polychlorinated naphthalenes from iron ore sintering processes. Chemosphere 89, 467-472.

Liu, G.R., Zheng, M.H., Du, B., Nie, Z.Q., Zhang, B., Hu, J.C., Xiao, K., 2012c. Identification and characterization of the atmospheric emission of polychlorinated naphthalenes from electric arc furnaces. Environ. Sci. Pollut. Res. 19, 3645-3650.

Liu, G.R., Zheng, M.H., Du, B., Nie, Z.Q., Zhang, B., Liu, W.B., Li, C., Hu, J.C., 2012d. Atmospheric emission of polychlorinated naphthalenes from iron ore sintering processes. Chemosphere 89, 467-472.

Liu, G., Zheng, M., Hu, J., Liu, W., Wang, M., Jiang, X., Gao, L., Nie, Z., 2013. Correlation analysis of unintentional polychlorinated naphthalenes with polychlorinated dibenzo-p-dioxins and dibenzofurans produced during industrial processes. Chin. Sci. Bull. 58. http://dx.doi.org/10.1360/972013-114.

Marti-Cid, R., Llobet, J.M., Castell, V., Domingo, J.L., 2008. Human exposure to polychlorinated naphthalenes and polychlorinated diphenyl ethers from foods in Catalonia, Spain: temporal trend. Environ. Sci. Technol. 42, 4195-4201.

Meijer, S.N., Harner, T., Helm, P.A., Halsall, C.J., Johnston, A.E., Jones, K.C., 2001. Polychlorinated naphthalenes in UK soils: time trends, markers of source, and equilibrium status. Environ. Sci. Technol. 35, 4205-4213.

Nie, Z.Q., Zheng, M.H., Liu, W.B., Zhang, B., Liu, G.R., Su, G.J., Lv, P., Xiao, K., 2011. Estimation and characterization of PCDD/Fs, dl-PCBs, PCNs, $\mathrm{HxCBz}$ and $\mathrm{PeCBz}$ emissions from magnesium metallurgy facilities in China. Chemosphere 85, 1707-1712.

Nie, Z.Q., Liu, G.R., Liu, W.B., Zhang, B., Zheng, M.H., 2012a. Characterization and quantification of unintentional POP emissions from primary and secondary copper metallurgical processes in China. Atmos. Environ. 57, 109-115.

Nie, Z.Q., Zheng, M.H., Liu, G.R., Liu, W.B., Lv, P., Zhang, B., Su, G.J., Gao, L.R., Xiao, K., 2012b. A preliminary investigation of unintentional POP emissions from thermal wire reclamation at industrial scrap metal recycling parks in China. J. Hazard. Mater. 215, 259-265.

Noma, Y., Yamamoto, T., Sakai, S.I., 2004. Congener-specific composition of polychlorinated naphthalenes, coplanar PCBs, dibenzo-p-dioxins, and dibenzofurans in the halowax series. Environ. Sci. Technol. 38, 1675-1680.

Noma, Y., Yamamoto, T., Giraud, R., Sakai, S., 2006. Behavior of PCNs, PCDDs, PCDFs, and dioxin-like PCBs in the thermal destruction of wastes containing PCNs. Chemosphere 62, 1183-1195.

Oh, J.E., Gullett, B., Ryan, S., Touati, A., 2007. Mechanistic relationships among PCDDs/Fs, PCNs, PAHs, CIPhs, and CIBzs in municipal waste incineration. Environ. Sci. Technol. 41, 4705-4710.

Olivero-Verbel, J., Vivas-Reyes, R., Pacheco-Londono, L., Johnson-Restrepo, B. Kannan, K., 2004. Discriminant analysis for activation of the aryl hydrocarbon receptor by polychlorinated naphthalenes. J. Mol. Struct. - Theochem. 678, 157161.

Park, H., Kang, J.H., Baek, S.Y., Chang, Y.S., 2010. Relative importance of polychlorinated naphthalenes compared to dioxins, and polychlorinated biphenyls in human serum from Korea: contribution to TEQs and potential sources. Environ. Pollut. 158, 1420-1427.

Puzyn, T., Falandysz, J., Jones, P.D., Giesy, J.P., 2007. Quantitative structure-activity relationships for the prediction of relative in vitro potencies (REPs) for chloronaphthalenes. J. Environ. Sci. Heal. A 42, 573-590.

Ryu, J.Y., Kim, D.H., Jang, S.H., 2013. Is chlorination one of the major pathways in the formation of polychlorinated naphthalenes (PCNs) in municipal solid waste combustion? Environ. Sci. Technol. 47, 2394-2400.

Sakai, S., Yamamoto, T., Noma, Y., Giraud, R., 2006. Formation and control of toxic polychlorinated compounds during incineration of wastes containing polychlorinated naphthalenes. Environ. Sci. Technol. 40, 2247-2253.

Schiavone, A., Kannan, K., Horii, Y., Focardi, S., Corsolini, S., 2010. Polybrominated diphenyl ethers, polychlorinated naphthalenes and polycyclic musks in human fat from Italy: comparison to polychlorinated biphenyls and organochlorine pesticides. Environ. Pollut. 158, 599-606.

Schneider, M., Stieglitz, L., Will, R., Zwick, G., 1998. Formation of polychlorinated naphthalenes on fly ash. Chemosphere 37, 2055-2070.

Schuhmacher, M., Nadal, M., Domingo, J.L., 2004. Levels of PCDD/Fs, PCBs, and PCNs in soils and vegetation in an area with chemical and petrochemical industries. Environ. Sci. Technol. 38, 1960-1969.

Sinkkonen, S., Paasivirta, J., Lahtipera, M., Vattulainen, A., 2004. Screening of halogenated aromatic compounds in some raw material lots for an aluminium recycling plant. Environ. Int. 30, 363-366.

Stanmore, B.R., 2004. The formation of dioxins in combustion systems. Combust. Flame 136, 398-427.

Takasuga, T., Inoue, T., Ohi, E., Kumar, K.S., 2004. Formation of polychlorinated naphthalenes, dibenzo-p-dioxins, dibenzofurans, biphenyls, and organochlorine pesticides in thermal processes and their occurrence in ambient air. Arch. Environ. Contam. Toxicol. 46, 419-431.

Tuppurainen, K., Halonen, I., Ruokojarvi, P., Tarhanen, J., Ruuskanen, J., 1998. Formation of PCDDs and PCDFs in municipal waste incineration and its inhibition mechanisms: a review. Chemosphere 36, 1493-1511.

Tuppurainen, K., Asikainen, A., Ruokojarvi, P., Ruuskanen, J., 2003. Perspectives on the formation of polychlorinated dibenzo-p-dioxins and dibenzofurans during municipal solid waste (MSW) incineration and other combustion processes. Acc. Chem. Res. 36, 652-658. 
Villeneuve, D.L., Kannan, K., Khim, J.S., Falandysz, J., Nikiforov, V.A., Blankenship, A.L., Giesy, J.P., 2000. Relative potencies of individual polychlorinated naphthalenes to induce dioxin-like responses in fish and mammalian in vitro bioassays. Arch. Environ. Contam. Toxicol. 39, 273-281.

Weber, R., Iino, F., Imagawa, T., Takeuchi, M., Sakurai, T., Sadakata, M., 2001. Formation of PCDF, PCDD, PCB, and PCN in de novo synthesis from PAH: mechanistic aspects and correlation to fluidized bed incinerators. Chemosphere 44, 1429-1438.
Xhrouet, C., De Pauw, E., 2004. Formation of PCDD/Fs in the sintering process: influence of the raw materials. Environ. Sci. Technol. 38, 4222-4226.

Yamashita, N., Kannan, K., Imagawa, T., Miyazaki, A., Giesy, J.P., 2000 Concentrations and profiles of polychlorinated naphthalene congeners in eighteen technical polychlorinated biphenyl preparations. Environ. Sci. Technol. 34, 4236-4241. 